\title{
Ao sul da fenda: notas acerca da relação entre teoria e prática no Serviço Social
}

\author{
Eduardo Mara ${ }^{1}$ \\ https://orcid.org/0000-0001-7241-8762 \\ ${ }^{1}$ Centro Universitário Joaquim Nabuco, Curso de Serviço Social, Recife, PE, Brasil
}

\section{Ao sul da fenda: notas acerca da relação entre teoria e prática no Serviço Social}

Resumo: A adoção do marco teórico marxista nos cursos de Serviço Social configura-se como parte fundamental da contestação ao conservadorismo na prática profissional. Contudo, o cotidiano do fazer profissional, pautado pelos interesses hegemônicos que demandam o trabalho dos assistentes sociais, segue apresentando a contradição entre os limites encontrados no cotidiano do trabalho profissional e as exigências da visão de mundo reivindicada pela profissão. Dessa forma, o presente artigo se propõe a analisar os desafios da relação entre teoria e prática no Serviço Social. O artigo está dividido em duas seções. Na primeira busca-se analisar a construção do método de análise nas obras de Karl Marx e sua importância para a relação entre teoria e prática. Na segunda seção analisamos o processo histórico de mudanças na profissão e a forma como a relação entre teoria e prática se colocaram para o Serviço Social no Brasil e na América Latina.

Palavras-chave: Serviço Social. Teoria e prática. Marxismo.

South of the crack: notes on the relationship between theory and practice in Social Work

Abstract: The adoption of the Marxist theoretical framework in Social Work courses is a fundamental part of the challenge to conservatism in professional practice. However, the daily routine of professional practice, guided by the hegemonic interests that demand the work of social workers, continues to present the contradiction between the limits found in the daily routine of professional work and the demands of the worldview claimed by the profession. Thus, this article aims to analyze the challenges of the relationship between theory and practice in Social Work. The article is divided into two sections. The first seeks to analyze the construction of the method of analysis in the works of Karl Marx and its importance for the relationship between theory and practice. In the second section we analyze the historical process of changes in the profession and the way in which the relationship between theory and practice has been placed for Social Work in Brazil and Latin America.

Keywords: Social work. Theory and practice. Marxism.

Recebido em 13.02.2020. Aprovado em 15.04.2020. Revisado em 26.06.2020.

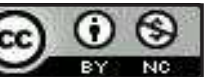

C O (s) Autor(es). 2020 Acesso Aberto Esta obra está licenciada sob os termos da Licença Creative Commons Atribuição-NãoComercial 4.0 Internacional (https://creativecommons.org/licenses/by-nc/4.0/deed.pt_BR), que permite copiar, distribuir e reproduzir em qualquer meio, bem como adaptar, transformar e criar a partir deste material, desde que para fins não comerciais e que você forneça o devido crédito aos autores e a fonte, insira um link para a Licença Creative Commons e indique se mudanças foram feitas. 


\section{Introdução}

Em Ao Sul da Fenda, Jack London (2005) nos conta a história de Freddie Drummond, um professor de Sociologia que, durante seis meses, transpunha a fenda que dividia a cidade de São Francisco entre o bairro nobre onde morava, ao norte, e os bairros operários e industriais, ao sul, com o objetivo de produzir uma pesquisa sobre hábitos e costumes da classe operária. Para isso, vivia uma dupla identidade: criara para si Bill Totts, um operário não qualificado que trabalhava nas indústrias ao sul, disfarce que lhe possibilitava conviver em meio à classe trabalhadora em suas aventuras de pesquisa. Ao atravessar a fenda, Freddie vestia a pele de Bill, incorporando os hábitos e costumes da classe operária, bem como comportamentos que seriam rechaçados em seu meio de origem, vivenciando a miséria e as contradições do chão de fábrica. Bill conquistara a simpatia e a confiança de seus colegas e tornara-se um companheiro, participando ativamente de greves e piquetes e contribuindo na própria organização sindical.

Não obstante, ao voltar ao norte, voltava também a ser Freddie, o intelectual conservador que produzia importantes e úteis pesquisas sobre o meio operário, que muito agradavam as grandes companhias de estradas de ferro. É para essa vida que decide voltar definitivamente ao terminar sua pesquisa, despedindo-se de Bill Totts e casando-se com alguém do seu meio social. O conto tem seu desfecho quando, ao atravessar a fenda agora como o próprio Freddie Drummond em seu automóvel acompanhado de sua elegante esposa, o personagem se vê cercado por uma manifestação da massa operária em greve onde vê seus colegas de outrora em choque com a polícia, e em "um urro que não era deste mundo, e muito menos do seu mundo" sai do carro deixando sua esposa, seu trabalho e sua vida ao norte da fenda: "Nos anos seguintes, não houve aulas de Freddie Drummond na Universidade da Califórnia, e não foi publicado nenhum livro seu sobre economia social" (LONDON, 2005 p. 129-131).

O conto de London nos oferece uma bela imagem do problema que queremos abordar. Quais são as linhas que separam os interesses de grupos sociais antagônicos e como situar-se diante desses interesses? Nossa intenção ao iniciarmos os estudos para o presente trabalho era de tratar da relação entre a tradição marxista e o Serviço Social. Chamou-nos a atenção o paradoxo de a teoria marxista, que tem como um dos seus núcleos mais dinâmicos a perspectiva da revolução, tornar-se marco teórico hegemônico no seio de uma profissão que surge "vocacionada para subsidiar a administração da questão social nos quadros da sociedade burguesa" (PAULO NETTO, 1989, p. 91).

Como profissão inscrita na divisão social e técnica do trabalho, o Serviço Social nasce da necessidade de ampliação da dominação burguesa na esfera do consenso, como forma de enfrentamento à questão social dentro dos limites da ordem do capital. Ela surge, portanto, com a missão de conciliar o inconciliável. Situase, por assim dizer, na fenda que separa projetos societários em confronto e sua ação pode tanto reforçar a ordem de coisas existente como vincular-se aos interesses das classes subalternas contribuindo na sua organização contra a ordem do capital. A questão é de que forma e em que conjunturas a prática profissional pôde ou pode posicionar-se dessa forma.

Este artigo visa, dessa forma, analisar a relação entre teoria e prática no Serviço Social a partir de dois problemas interdependentes: de um lado, a incorporação do marxismo pelo Serviço Social acabou por trazer uma tensa relação com a exigência de intervenção prática na realidade contida na própria obra marxiana, onde a interpretação do real é inseparável de sua transformação. De outro, o constante desafio em traduzir aquela opção teórica em linhas de intervenção práticas na realidade pela prática profissional, realidade que se transforma condicionada pelas diferentes relações de força entre as classes e frações de classe e a partir das diferentes estratégias de dominação mobilizadas pelas classes dominantes.

Trata-se de entender como a teoria adquire força material servindo de alimento à prática social e como a prática pode servir de subsídio à reflexão teórica. Começaremos por uma análise dessa relação na própria obra marxiana. Tal análise é essencial para entendermos o processo de aproximação do Serviço Social com a tradição marxista, seu significado e também suas possíveis lacunas e contradições. É o que tentaremos fazer na segunda parte do artigo. Por fim, analisaremos os problemas colocados em debate hoje sobre a relação entre teoria e prática no Serviço Social.

\section{Teoria e prática na obra de Marx}

A atualidade do recurso à obra de Marx (2009; 2008; 2008a; 2010) consiste não apenas em sua capacidade de operar a fusão entre três diferentes esferas do conhecimento (a filosofia alemã, a economia inglesa e a política francesa), mas também na síntese teórica entre três dimensões constituintes da própria modernidade capitalista, a saber: a razão dialética, a centralidade do trabalho e a perspectiva da revolução. 
De forma esquemática, poderíamos dizer que essas três dimensões correspondem, no tempo e no espaço, à apropriação das três fontes citadas: do contato com a filosofia alemã e da crítica ao sistema filosófico de Hegel, Marx teria extraído seu método (o materialismo dialético); da crítica da economia política clássica inglesa, Marx teria extraído sua análise sobre a teoria do valor-trabalho e, por fim, o contato com o socialismo francês seria a base de sua teoria da revolução.

Esse esquema, no entanto, acaba por compreender a dimensão do método, da análise do modo de produção e da análise do movimento das classes como esferas em separado conduzindo a interpretações e divisões equivocadas da obra marxiana. Se é evidente que esta vai adquirindo maior complexidade em sua trajetória, não é menos verdade que é impossível entendermos sua análise do modo de produção capitalista contida em O Capital (MARX, 1988), se não levarmos em conta o movimento de seu pensamento da crítica à filosofia especulativa à crítica da economia política. Cada momento desse caminho supera ao mesmo tempo incorporando os elementos anteriores, ou seja, a obra marxiana também deve ser entendida em sua totalidade.

Uma leitura responsável da obra de Marx deve começar pela análise das linhas de ruptura e continuidade que distinguem o seu pensamento da filosofia de Hegel. Ao escrever sua Contribuição à crítica da Filosofia do Direito de Hegel-Introdução, aos 25 anos, Marx (2010) já antevê algumas das problemáticas centrais que ressurgirão em obras posteriores. A crítica ao conceito de Estado em Hegel é o primeiro momento de inversão da própria lógica Hegeliana. Em Hegel o Estado aparece como a síntese da contradição entre a ideia, o movimento do Espírito do Mundo, e a sociedade civil em cada época histórica (apud MARX, 2010). Ao inverter essa lógica, Marx (2010) passa a procurar a contradição existente no próprio mundo (e não no desenvolvimento do pensamento), ou seja, no seio da sociedade civil. A contradição entre o progresso das ideias universais e a realidade social, representada na mente do filósofo não eram mais do que a expressão ideal de forças sociais reais em conflito na sociedade civil. Era preciso entender o que determinava esse conflito passando, portanto, ao estudo da economia política.

O problema da relação entre teoria e prática aparece na crítica ao anacronismo da sociedade alemã que acreditava realizar a modernidade em seus debates filosóficos pela impossibilidade de superar o estado de coisas vigente na prática. Afirma que as revoluções não brotam ou se desenvolvem na cabeça dos intelectuais, mas precisam de um fundamento material e esse fundamento são classes sociais com projetos societários em confronto. Não apenas a filosofia especulativa do Estado em Hegel, mas também o pensamento de seus opositores, eram o reflexo da ausência de uma classe social que pudesse impulsionar aquelas transformações como a expressão dos interesses universais do povo alemão (MARX, 2010).

$\mathrm{Na}$ França assim como na Inglaterra, a burguesia havia feito revoluções apresentando seus interesses particulares de classe como interesses universais porque estes encarnavam, de fato, interesses universais naquele período histórico. Para isso ela teve de arrastar para a luta contra o antigo regime os camponeses pobres e o proletariado em formação. Contudo, a sociedade alemã não havia vivenciado os processos de transformação da sociedade moderna, embora já vivenciasse suas mazelas. A burguesia alemã não podia cumprir aquele papel revolucionário sem colocar em risco a sua própria dominação estimulando o proletariado para a arena da política. A superação que aparecia nos debates filosóficos tinha de encontrar substrato material em outra classe que, em suas condições objetivas de existência, fizesse coincidir seus interesses de classe com interesses universais.

Essa classe só podia ser, nas condições alemãs, o proletariado em formação. Aquilo que Hegel identificava como o movimento do espírito não era senão o conflito entre forças sociais reais em movimento na História. Marx precisava encontrar na sociedade civil as formas profanas da disputa que os alemães sublimavam no pensamento, mas precisava também encontrar nessas forças sociais reais o fundamento de suas próprias ideias. Daí que a noção de proletariado e de classes sociais tenham aqui ainda contornos pouco precisos. O importante é que as ideias já aparecem como reprodução do movimento contraditório do real, seus fundamentos devem ser buscados na contradição existente entre sujeitos concretos que se movem no seio da sociedade civil.

Era necessário completar a crítica ao idealismo da dialética Hegeliana com a crítica ao materialismo naturalista de sua época. A noção de práxis adquire, nas Teses sobre Feuerbach, todo o seu significado. Feuerbach queria separar sujeito e objeto do conhecimento, objetividade e pensamento. Para Marx (2009), a virtude do idealismo era a de ter percebido o lado ativo do ser humano na História, mas esse lado ativo também aparecia de forma unilateral: o real sendo constituído pelo pensamento. O próprio ato de conhecer o mundo é, para Marx (2009), atividade humana prático-sensível, ou seja, não existe natureza para os seres humanos em separado de sua ação sobre ela. Conhecer é fazer. O processo de conhecimento é, portanto, uma atividade comum da espécie onde os seres humanos forjam a própria objetividade: e eles o fazem através do trabalho.

Somente o ser humano é capaz de partir das contradições inscritas nas linhas do presente e prefigurar soluções em sua mente, modificando a natureza a partir de um plano pré-estabelecido e, com isso, modifi- 
cando sua própria natureza. A categoria trabalho em Marx é, dessa forma, a síntese entre objetividade e subjetividade, entre pensamento e ação, entre determinação e sujeito. A centralidade do trabalho é inseparável do método marxiano de compreensão da realidade.

A conhecida Introdução à Contribuição à Crítica da Economia Política (MARX, 2008a) está longe de ser, portanto, um tratado sobre o método. O que nos parece central é a recuperação da dialética não mais como movimento do pensamento, mas como a forma do pensamento se apropriar do movimento concreto do real. $\mathrm{O}$ concreto é concreto por ser síntese de múltiplas determinações, ou seja, síntese de relações sociais diversas, mas que constituem uma unidade em seu movimento na História. O procedimento laboratorial com que operava a economia política acabava por isolar e classificar elementos que correspondem a momentos diferenciados de um mesmo movimento histórico e que, portanto, só podem ser entendidos como totalidade.

Não se trata de utilizar o universal como princípio explicativo do particular, como se houvesse uma externalidade entre ambos. Aquilo que aparece na realidade imediata em sua forma singular (a população, a família, o Estado, as classes etc.) não são mais que formas particulares de uma universalidade, ou seja, o particular contém o universal, ele é em si mesmo a expressão da totalidade das relações sociais nas quais se insere. Por isso, as classes sociais não são um simples reflexo da contradição entre a produção social e as relações sociais, a luta entre elas é justamente a principal manifestação concreta dessa contradição.

Daí a necessidade de, após elevar-se das formas abstratas dos fenômenos sociais (a forma como se apresentam em sua singularidade imediata) para suas formas mais concretas (universais), fazer a viagem de volta ao ponto de partida "não mais como uma representação caótica de um todo, porém como uma rica totalidade de determinações e relações diversas" (MARX, 2008a, p. 256). É esse retorno que permite à teoria não apenas interpretar o real, mas entender-se como um momento de sua transformação, por ser expressão de forças sociais reais que se apropriam do mundo transformando-o. Sem isso, ficaríamos com as determinações mais gerais produzidas pelo movimento abstrato do pensamento que não têm em si mesmas, nenhum poder de intervenção sobre o real.

A dialética não está no pensamento, mas na realidade e, o mais importante, não em qualquer realidade, mas na sua forma mais desenvolvida: a sociedade burguesa moderna. A sociedade capitalista não surge como produto de uma sequência linear de causalidades históricas, ela é uma síntese temporal que permite a compreensão das formas mais simples que ela mesma incorpora no presente. E é também somente nessa sociedade que se torna possível a síntese operada por Marx entre teoria e prática, onde se torna possível ao pensamento abarcar o movimento contraditório do real, porque somente nessa época histórica surge uma classe cuja condição de existência se baseia na transformação constante do próprio modo de produção.

Esses são os pressupostos que devemos levar em conta ao ler o Prefácio à Contribuição à Crítica da Economia Política de 1859. O resumo esquemático do texto ainda enseja confusões de interpretação que, a nosso ver, se devem principalmente ao fato de não se levar em conta a unidade contida na obra marxiana. Como vimos, a análise da economia política em Marx (2008a) é inseparável de sua análise do movimento das classes num determinado período histórico. Em outras palavras, não há uma separação estanque entre economia e política na obra marxiana. Se é imprescindível a análise da contradição inerente ao modo de produção capitalista é porque esta delimita o campo e as possibilidades de enfrentamento entre classes sociais que são, ao mesmo tempo, fundamento e expressão daquela mesma contradição, são as forças sociais reais que dão movimento à estrutura social podendo transformá-la.

Uma leitura apressada deste texto pode produzir interpretações catastróficas. Nele, "a vida social, política e intelectual" aparece como condicionada ao "modo de produção da vida material" (MARX, 2008a, p. 45). Dito de outra forma, se a consciência aparece determinada pelas relações sociais vividas, ela tenderia, portanto, a reproduzir essas mesmas relações. Em se tratando de relações de dominação ela não poderia alçar voos maiores do que a reprodução dessa mesma dominação. Da mesma forma, a política não seria senão o reflexo da estrutura econômica. Nessa acepção, os seres humanos desaparecem como produtores de sua própria história, cujo agente passaria a ser as "forças produtivas materiais". No entanto, cabe observar que Marx inicia o texto recuperando justamente a concepção de que os seres humanos são produtores e produtos de sua própria existência. Para lembrarmos a conhecida passagem de O 18 Brumário de Luís Bonaparte, "os homens fazem a sua própria história, mas não a fazem segundo a sua livre vontade, em circunstâncias escolhidas por eles próprios, mas nas circunstâncias imediatamente encontradas, dadas e transmitidas pelo passado" (MARX, 2008, p. 207).

Quanto à consciência, essa não é um simples reflexo das relações de produção, mas a expressão ideal das contradições que emanam dessas mesmas relações. Abre-se a possibilidade de uma defasagem entre as ideias anteriormente introjetadas pela ideologia dominante e a vivência mesma das relações sociais de dominação. Se deve distinguir entre o que os seres humanos dizem ser (as formas ideológicas que dão significado à sua ação no plano imediato) do que são realmente porque o que são deve ser explicado, não apenas pelo modo 
de produção como uma fotografia estática do real, mas "pelas contradições da vida material, pelo conflito que existe entre as forças produtivas materiais e as relações de produção” (MARX, 2008a, p. 46).

\begin{abstract}
Em uma certa etapa do seu desenvolvimento, as forças produtivas materiais da sociedade entram em contradição com as relações de produção existentes, ou, o que não é mais do que sua expressão jurídica, com as relações de propriedade no seio das quais se haviam desenvolvido até então. De formas evolutivas das forças produtivas que eram, essas relações convertem-se em entraves. Abre-se, então, uma época de revolução social. (MARX, 2008a, p. 45).
\end{abstract}

Note-se que o conceito de revolução em Marx não se resume a um momento de irrupção na história, trata-se de uma época de revolução social aberta pela própria contradição entre a produção da riqueza e sua apropriação privada em uma sociedade dividida em classes. Se a tomada revolucionária do poder de Estado e o controle dos meios de produção são aspectos inseparáveis da revolução socialista em Marx, esta não se resume a esses momentos. Trata-se de todo o processo de constituição das classes em luta pelo poder que não se inicia, nem termina na tomada do poder de Estado (embora siga sendo um momento determinante).

Não é ocasional que Marx (2008a, p. 46) analise essa época aberta de revolução social distinguindo a "transformação material das condições econômicas de produção" das formas ideológicas, sinalizando que é através dessas últimas que "os homens adquirem consciência desse conflito e o levam até o fim”. Não há uma separação estanque entre estrutura e superestrutura. As formas jurídicas, políticas e ideológicas são também aspectos determinantes do processo de reprodução social nas quais podemos entender o movimento entre as classes. Os seres humanos seguem como sujeitos de sua História porque são seres conscientes atuando sobre as contradições vividas para além da forma como elas se apresentam na realidade imediata. As classes sociais são, como a categoria trabalho, junção entre objetividade e subjetividade, determinação e liberdade. Se definem pelo lugar que ocupam nos meios de produção sendo, a um só tempo, forças produtivas materiais e forças em luta pelo poder em cada conjuntura histórica. O que dá unidade e também confere movimento à estrutura social são sujeitos sociais coletivos capazes de traduzir aquela contradição, que brota da produção social de suas vidas, em formas ideopolíticas, projetos societários em confronto na sociedade civil, agindo sobre as relações sociais para transformá-las (MARX, 2008b).

O socialismo não é uma consequência do desenvolvimento do modo de produção. O texto de Marx (2008a) é bastante claro: é a humanidade que segue podendo alterar o curso de sua História, mas ela o faz a partir das contradições acumuladas pelas gerações que a antecederam. Há aqui não apenas uma semelhança com o conceito de trabalho, mas uma identidade: o desenvolvimento das forças produtivas materiais (que significa também o desenvolvimento das classes sociais fundamentais) coloca novas possibilidades de sua transformação, possibilidades a partir das quais a humanidade pode projetar no pensamento possibilidades de superação. Em outras palavras, os projetos societários apresentados pelas classes sociais em luta não nascem da cabeça dos filósofos, eles são expressão das possibilidades que já se encontram em desenvolvimento na própria realidade. O método marxiano é inseparável de sua concepção sobre a centralidade do trabalho e ambos só são entendidos na relação específica entre teoria e prática no interior de uma perspectiva revolucionária.

Dessa forma, a tomada de posição e a vinculação ao projeto societário das classes subalternas é um pressuposto contido no próprio método. A reprodução do movimento da realidade pelo pensamento é também a reprodução de uma contradição contida nesse movimento, contradição de onde brotam projetos societários em confronto na sociedade civil. A análise do desenvolvimento do modo de produção capitalista só se completa e ganha sentido, portanto, com a análise do movimento das classes e da correlação de forças entre elas em cada período. Podemos, finalmente, ir direto ao ponto: é isso que entendemos por centralidade da política na tradição marxista. E este é o aspecto fundamental que permite a essa tradição equacionar a relação entre teoria e prática.

Não basta que a teoria tenda para a realidade, é necessário que a realidade tenda para a teoria. A luta de classes segue sendo a mediação fundamental a partir da qual se desenham os limites, avanços e recuos da teoria. Exatamente por situar-se na fenda que separa interesses antagônicos das classes sociais em luta, a relação entre teoria e prática no fazer profissional também deve ser entendida a partir da correlação de forças 
existente entre as diferentes classes ou, dito de outra forma, a partir da maneira como as classes fundamentais formulam seus projetos societários e se colocam na cena política a cada conjuntura histórica.

\section{O Marxismo e o Serviço Social}

A própria definição do Serviço Social com a qual estamos trabalhando é inseparável de sua aproximação com a tradição marxista. Somente com as transformações societárias ocorridas na América Latina a partir da segunda metade da década de 1960 se tornou possível ao Serviço Social refletir sobre o papel ocupado pela profissão no seio de uma sociedade dividida em classes.

O primeiro contato significativo do marxismo com o serviço social dá-se, assim, no bojo do movimento de reconceituação na América Latina. Entender a gênese desse movimento é também entender a redefinição da profissão e os novos desafios colocados à relação entre teoria e prática. Uma análise mais aprofundada do movimento de reconceituação excede, contudo, os limites daquilo a que nos propomos analisar nesse artigo. Basta salientar que será o contexto de efervescência das lutas sociais no continente que determinará o viés dessa aproximação através do engajamento político da profissão nas lutas sociais, bem como serão as próprias questões colocadas pela luta de classes na América Latina naquele período que determinariam, dentro da diversidade de concepções existentes, a necessidade do recurso à tradição marxista.

Da mesma forma, o surgimento do Serviço Social não pode ser entendido somente nos marcos da transição do capitalismo concorrencial para a ordem monopólica. Se essa passagem delimita os contornos das contradições de classe e da ação do Estado na qual surge o serviço social como profissão, ela é também determinada pelo enfrentamento entre as classes e frações de classe no período que a antecede e pelos projetos societários que expressam esse conflito. Segundo Paulo Netto (2001), tal transição, cujo ponto de partida pode ser datado da reação burguesa às revoluções de 1848, concretizara três fenômenos que delimitaram os contornos dos agentes históricos e dos embates fundamentais entre eles dali para frente: "o proletariado constituído como classe para si, a burguesia operando estrategicamente como agente social conservador e o peso específico das classes e camadas intermediárias" (PAULO NETTO, 2001, p. 54).

O crescente protagonismo do proletariado, agora munido de instrumentos de conversão de suas lutas econômicas imediatas em projeto político (sindicatos e partidos de massa) redimensiona as estratégias de dominação burguesas que "agora tem de enfrentar lutas políticas de massas, perpassadas por um projeto político-social que trava combates pela direção da sociedade"( PAULO NETTO, 2001, p. 60).

A preponderância do capital industrial e financeiro na era dos monopólios traz consigo, dessa forma, a necessidade de conter a questão social dentro dos limites da ordem do capital, de onde provém a necessidade do próprio profissional do Serviço Social. Dominar pelo consenso significa, em grande medida, a capacidade das classes dominantes em travestir seus interesses particulares de classe em interesses universais, o que implica a capacidade de absorver, ainda que parcialmente, através do Estado ou de aparelhos da sociedade civil, reivindicações das classes subalternas. Como afirma Iamamoto e Carvalho (2014), a profissão dos assistentes sociais é entrecortada pelos interesses das instituições que demandam e remuneram seus serviços, sob controle direto ou indireto da classe dominante, e aqueles para quem esse serviço se destina, a classe trabalhadora. Embora as políticas sociais sejam fruto da luta e resistência dos de baixo, sua incorporação responde a interesses próprios da manutenção da dominação dos de cima, transformando conquistas em concessões e apaziguando as tensões inerentes às contradições de classe. Cria-se, assim, uma disjunção entre os reais interesses que demandam o trabalho dos Assistentes Sociais e aqueles aos quais se destina os seus serviços.

O que nos interessa aqui é que esse entendimento mesmo da funcionalidade da profissão aos interesses de manutenção da ordem burguesa só se torna possível em uma conjuntura de crise dessa mesma ordem, crise que abre possibilidades ao corpo profissional identificar-se com os interesses das classes subalternas contestando o conservadorismo no interior da profissão.

A industrialização levada a cabo nos estreitos limites da manutenção do domínio imperialista no continente tinha como contraface o aumento da força social da classe trabalhadora urbana que forçava sua entrada na História expondo as contradições da burguesia associada e dependente. É esse ambiente de convergência das lutas anti-imperialistas na América Latina que irá minar as bases de sustentação do serviço social tradicional e configurar as problemáticas centrais do movimento de reconceituação, bem como a diversidade de concepções presentes e a necessidade do recurso à tradição marxista. Não é à toa que a questão do desenvolvimento se colocava como um divisor de águas: esta era a questão fundamental situada na fenda entre projetos de classe antagônicos. Daí a contraposição do projeto de modernização conservadora, ao norte, às alternativas reformistas-democráticas e à vertente propriamente revolucionária. $\mathrm{O}$ processo de ruptura com o conservadorismo na profissão seria interrompido, justamente, pelo caminho ditatorial encontrado pela burgue- 
sia desses países como forma de conter o desenvolvimento nos estreitos limites de sua herança colonial e das exigências do capital financeiro internacional.

Essa primeira aproximação com o marxismo tem, portanto, fundamento na própria dinâmica da luta de classes no período. Esta é que fornecerá a base material à exigência de um novo marco teórico para lidar com a questão social, que se apresentava agora como demandas concretas de sujeitos coletivos em luta. Entretanto, se o filtro da militância política acabara por impulsionar essa aproximação à tradição marxista, ele seria responsável também por suas lacunas e limites. A ideia de que o engajamento nas lutas sociais poderia, por si só, levar à consciência teórica dos fundamentos da dominação capitalista teria demarcado certo utilitarismo e ecletismo na utilização das fontes, com um destaque para o escasso recurso aos originais da obra marxiana. Cria-se assim um fosso entre as intenções expressas pela prática política e seus fundamentos teóricos, sintetizado por Iamamoto nas tendências fatalistas, onde o poder é tido como algo monolítico e o próprio serviço social como necessariamente subjugado aos interesses dominantes, e no messianismo, marcado pelo voluntarismo político incapaz de apreender o movimento do real sobre o qual atua (PAULO NETTO, 1991; IAMAMOTO, 2004).

É interessante notar a alteração que se daria nesse quadro e o protagonismo brasileiro no contexto de crise da ditadura. As contradições que se avolumaram durante o desenvolvimento impulsionado pelos regimes militares fizeram emergir, em fins da década de 1970, a luta de classes que estava contida nos subterrâneos da arena político-institucional. É o forte movimento democrático-popular da década de 80 que forneceria um solo fértil para que o Serviço Social reapresentasse em novo patamar as questões colocadas pela reconceituação aprofundando a relação com a tradição marxista. É a partir da vinculação entre a vanguarda teórica e política da profissão e o movimento democrático-popular que o Serviço Social irá se consolidar como espaço de produção de saberes, formular seu código de ética e seu projeto ético-político.

O amadurecimento teórico na relação com a tradição marxista teria, assim, desenvolvido sua maturidade em estreita relação com aquele movimento em ascensão. O desafio que se colocava então era traduzir essa orientação teórica em linhas de intervenção prática na realidade por parte dos profissionais. Nos últimos anos da década de 1980 e início da década de 1990 ocorre, no entanto, a convergência de três processos que iriam alterar, em nossa opinião, a relação entre teoria e prática que vinha sendo desenvolvida: a crise do socialismo real no leste europeu, a reestruturação produtiva e a ascensão do neoliberalismo.

Apesar da conjuntura desfavorável às ideias de Marx oriundas da falência do socialismo no leste, Paulo Netto (1991) antevia uma progressiva incorporação da tradição marxista na formação dos profissionais, a partir do desenvolvimento já alcançado, mas também pelos condicionantes que extrapolam a profissão, com destaque para o crescente protagonismo da classe trabalhadora herdada da década de 1980 e às exigências de crítica do padrão excludente do desenvolvimento periférico.

A década de 1990 iria relativizar enormemente esse prognóstico, não obstante tenha se materializado nessa época bases sólidas de contestação ao serviço social tradicional. Se de um lado, de fato, a tradição marxista se consolida como referencial teórico hegemônico nos cursos de graduação e pós-graduação, esta já não encontra o mesmo eco no exercício da profissão. É que a possibilidade de o profissional do Serviço Social identificar-se com um projeto societário alternativo à ordem do capital e traduzir esta identidade em linhas de intervenção profissional não depende apenas do marco teórico de sua formação, mas principalmente da correlação de forças encontrada na luta de classes a cada período.

A ascensão do neoliberalismo, combinada com a desindustrialização e a reestruturação produtiva iriam minar nos anos 90 o protagonismo proletário acima referido, desmontando também a base social do sindicalismo combativo. Consolida-se um novo trato com a Questão Social, onde as demandas voltam a se apresentar na perspectiva da refilantropização das reivindicações de classe, diante das quais exige-se do profissional a filtragem das demandas dentro das estreitas possibilidades colocadas por esta ou aquela política pública.

A questão passa a ser como orientar a intervenção profissional de acordo com projetos sociais coletivos da classe trabalhadora no momento em que esta não se apresenta sequer como classe em si, ou seja, onde a própria luta de classes deixa de ter contornos mais nítidos. Cria-se, dessa forma, a sensação de uma defasagem agora não mais entre as intenções colocadas pela prática profissional, mas entre os pressupostos da teoria e a vivência da prática profissional, criando a impressão de que na prática, a teoria é outra. Se tal afirmação, característica do senso comum, parece ganhar sentido entre os profissionais, acreditamos que de nada nos adianta manifestar-se teoricamente contra ela, se não entendermos a base real na qual se sustenta. Segundo Forti e Guerra (2010), tal afirmativa têm origem em concepções equivocadas dos assistentes sociais acerca de seu trabalho, reforçando o pragmatismo no interior da profissão e valorizando uma noção de prática que nega a importância da teoria. Caberia ao profissional do serviço social desvencilhar-se do senso comum, apropriando-se das teorias macroscópicas que possibilitem um maior conhecimento da realidade onde atua.

Não entendemos por senso comum uma mera falsificação do real, mas a forma compósita com a qual os seres humanos constroem sua visão de mundo a partir da realidade vivenciada de forma imediata. Em 
outras palavras, o que dá força e sentido ao senso comum é a sua correspondência com a realidade vivida. Dessa forma, não é uma alternativa do profissional simplesmente livrar-se do senso comum através do conhecimento teórico. O conhecimento teórico da realidade não pode minar a base de sustentação do senso comum sem transformá-la na prática.

As autoras inserem como requisito imprescindível do trabalho profissional do assistente social a "capacidade de captar criticamente essa realidade social que é contraditória e dinâmica, o que pressupõe a busca de superação teórica, política e ética" (FORTI; GUERRA, 2010, p. 8). Contudo, se entendemos o Assistente Social como um intelectual subalterno aos interesses da dominação burguesa (IAMAMOTO; CARVALHO, 2014, p. 95) que "recebe assalariamento em função da requisição patronal/institucional de participar no sentido de viabilizar a subordinação do trabalho à produção/ao capital" (FORTI; GUERRA, 2010, p. 8), tal capacidade não se insere como requisito por parte daqueles que demandam o trabalho profissional. Ao contrário, nos parece que essa tarefa exige desse profissional justamente restringir sua prática ao domínio da própria imediaticidade, que encobre o movimento do real e, portanto, as contradições entre interesses antagônicos nos quais sua ação profissional se insere.

Como vimos a exigência contida no método marxiano em apreender o real como totalidade é indissociável da vinculação a um projeto societário contra-hegemônico. Se a presença da tradição marxista na formação profissional traz consigo essa exigência, a teoria não tem, por si só, condição de alterar a prática profissional. É que há, de fato, uma distância entre a teoria e as possibilidades que este profissional encontra de vinculação de sua prática a um projeto contra-hegemônico. As possibilidades de enxergar o seu fazer profissional situado na fenda que separa interesses de classe depende da dinâmica da própria luta de classes. As classes sociais mesmas se forjam nessa luta. O profissional possui uma dimensão intelectual, mas é o próprio movimento da realidade que serve de alimento à teoria.

A possibilidade de posicionar teoria e prática ao sul da fenda diante da escolha entre projetos societários distintos depende da constituição do proletariado como classe para si ou, em outros termos, depende da passagem da luta de sua fase econômico-corporativa para o momento propriamente ético-político. É isso o que explica o fosso momentâneo entre teoria e prática, colocando a primeira como elemento secundário:

No processo, porém, repetem-se continuamente momentos nos quais entre a massa e os intelectuais (ou alguns deles, ou um grupo deles) se produz uma separação, uma perda de contato, e, portanto, a impressão de "acessório", de complementar, de subordinado. A insistência sobre o elemento "prático" da ligação teoria-prática - após se ter cindido, separado e não apenas distinguido os dois elementos (o que é uma operação meramente mecânica e convencional) - significa que se está atravessando uma fase histórica relativamente primitiva, uma fase ainda econômico-corporativa, na qual se transforma quantitativamente o quadro geral da "estrutura" e a qualidade-superestrutura adequada está em vias de surgir, mas não está organicamente formada. (GRAMSCI, 1999, p. 105).

A unidade entre teoria e prática não se dá de forma imediata e individualizada, ela é, segundo Gramsci, um devir histórico. Não se trata de um condicionamento mecânico do pensamento pelos limites da prática a cada conjuntura, trata-se, como vimos, de levar a cabo a tarefa de converter as ideias em força material de transformação das condições existentes ou, nas palavras de Gramsci, transformar a filosofia em vida. A vinculação dos intelectuais à uma classe social passa, assim, por elaborar e tornar "coerentes os princípios e os problemas que aquelas massas colocavam como a sua atividade prática, constituindo um bloco cultural e social" (GRAMSCI, 1999, p. 100).

\section{Considerações Finais}

O enfrentamento ao conservadorismo no interior da profissão passa, nos dias atuais, pela necessidade de recuperar o que acreditamos ser o núcleo central que fornece a vitalidade da tradição marxista: a centralidade da política, aqui entendida como a análise da correlação de forças entre as classes a cada conjuntura, o que é a principal expressão concreta das contradições que brotam de uma estrutura social. Trata-se de entender o nível de consciência alcançado pelos trabalhadores e o modo como formulam suas reivindicações a cada período e como orientar a prática profissional a auxiliar no processo de constituição do proletariado em classe. O próprio objeto de trabalho do assistente social comporta essa possibilidade. Como afirma Iamamoto (2004, p. 28), a questão social "sendo desigualdade é também rebeldia". Exatamente por terem seu trabalho situado entre interesses de classe distintos torna-se possível rebelar-se contra as exigências de manutenção da sociedade burguesa. 
Em uma conjuntura de aumento progressivo da barbárie social, o desafio lançado pela autora de decifrar as novas mediações pelas quais se expressa a questão social adquire uma certa urgência. Revelar no interior das contradições as possibilidades de resistência e organização que já se encontravam latentes no próprio cotidiano vivido pela classe trabalhadora, é o que permite, transformarem o posicionamento de classe presente em sua formação em linhas de intervenção consequentes no cotidiano do fazer profissional.

Acreditamos, por fim, que a ruptura definitiva com o conservadorismo na prática profissional é também, assim como a unidade entre teoria e prática, um devir histórico. Ela exige não só que o profissional do serviço social transite ao sul da fenda vinculando-se aos problemas vividos pela classe trabalhadora. Ela exige também e principalmente, para ficarmos com a bela imagem que resgatamos de Jack London no início desse artigo, que a própria classe possa romper com os limites da vida cotidiana desse profissional, rompendo as barreiras da própria dominação. É necessário que a teoria possa ser superada pela História.

\section{Referências}

FORTI, V.; GUERRA, Y. (org.). Serviço Social: Temas, textos e contextos. Rio de Janeiro: Lumen Juris, 2010.

GRAMSCI, A. Cadernos do cárcere, volume 1. Rio de Janeiro: Civilização Brasileira, 1999.

IAMAMOTO, M. V. O serviço social na contemporaneidade: trabalho e formação profissional. São Paulo: Cortez, 2004.

IAMAMOTO, M. V.; CARVALHO, R. Relações sociais e serviço social no Brasil: esboço de uma interpretação histórico-metodológica. São Paulo: Cortez, 2014.

LONDON, J. Contos. São Paulo: Expressão Popular, 2005.

MARX, K. A ideologia alemã. São Paulo: Expressão Popular, 2009.

MARX, K. A revolução antes da revolução. São Paulo: Expressão Popular, 2008.

MARX, K. Contribuição à critica da economia política. São Paulo: Expressão Popular, 2008a.

MARX, K. Contribuição à crítica da filosofia do direito de Hegel: introdução. São Paulo: Expressão Popular, 2010.

MARX, Karl. O Capital. Vol. 1. São Paulo, Nova Cultural, 1988.

PAUlO NETTO, J. Capitalismo Monopolista e Serviço Social. São Paulo, Cortez, 2001.

PAULO NETTO, J. Notas sobre marxismo e Serviço Social, suas relações no Brasil e a questão de seu ensino. In: CADERNOS ABESS IV. Ensino em Serviço Social: Pluralismo e Formação Profissional. São Paulo: Cortez, 1991.

PAULO NETTO, J. O Serviço Social e a tradição marxista. Serviço Social \& Sociedade, São Paulo, ano 10, n. 30, p. 89-102, maio/ago. 1989.

\section{Eduardo Mara}

dumaraseso@gmail.com

Doutor em Serviço Social pela Universidade Federal de Pernambuco (UFPE)

Docente do Centro Universitário Joaquim Nabuco (UNINABUCO)

\section{UNINABUCO}

Rua Francisco Vitta, 385 - apto 102. Cordeiro.

Recife - PE - Brasil

CEP: 50630-190

Agradecimentos

Não se aplica.

Agência financiadora

Não se aplica.

Contribuições das autoras

Não se aplica.
Aprovação por Comitê de Ética e consentimento para participação

Não se aplica.

Consentimento para publicação

Consentimento do autor.

Conflito de interesses

Não há conflito de interesses. 